\title{
2008/40
}

Transportation, freight rates, and economic geography

Kristian Behrens and Pierre M. Picard 
CORE

Voie du Roman Pays 34

B-1348 Louvain-la-Neuve, Belgium.

Tel (32 10) 474304

Fax (32 10) 474301

E-mail: corestat-library@uclouvain.be http://www.uclouvain.be/en-44508.html 


\title{
CORE DISCUSSION PAPER
}

$2008 / 40$

\section{Transportation, freight rates, and economic geography}

\author{
Kristian BEHRENS ${ }^{1}$ and Pierre M. PICARD ${ }^{2}$
}

July 2008

\begin{abstract}
We investigate the role of the transport sector in structuring the location of economic activity within two-region economic geography models of the footloose capital and core-periphery types. In our setting, competitive carriers offer transport services for shipping manufactured goods across regions and freight rates are determined endogenously to clear transport markets. Each carrier commits to the maximum capacity for a round-trip and thus faces a simple logistic problem: there are costs associated with 'returning empty', and those costs increase the freight rates charged to manufacturing firms. Since demand for transport services depends on the spatial distribution of economic activity, agglomeration in one region raises freight rates to serve foreign markets, thus generating an additional dispersion force. We show that a more equal equilibrium distribution of firms prevails when freight rates are endogenously determined than when they are exogenous and that multiple equilibria (including partial agglomeration) usually coexist.
\end{abstract}

Keywords: transport sector, freight rates, economic geography, trade.

JEL Classification: F12, R12

\footnotetext{
${ }^{1}$ Department of Economics, Université du Québec à Montréal (UQAM), Canada. E-mail: Behrens.kristian@uqam.ca

${ }^{2}$ SoSS, University of Manchester, UK and CORE, Université de Louvain, Belgium. E-mail: Pierre.picard@manchester.ac.uk
}

We thank Pierre-Philippe Combes, Giordano Mion, Michael Pflüger, Frédéric Robert-Nicoud, Jacques Thisse, and participants at the $54^{\text {th }}$ North American Meetings of the RSAI in Savannah for helpful comments and suggestions. Kristian Behrens gratefully acknowledges financial support from the Université du Québec à Montréal. All remaining errors are ours.

This paper presents research results of the Belgian Program on Interuniversity Poles of Attraction initiated by the Belgian State, Prime Minister's Office, Science Policy Programming. The scientific responsibility is assumed by the authors. 

It is fair to say that transport costs and factor mobility are the two key ingredients that set apart the 'new economic geography' (henceforth, NEG) from conventional trade theory. One might thus quite naturally expect that a detailed analysis of their determinants and economic consequences has figured prominently on the research agenda in this field. While this is partly true for factor mobility, transport costs have usually been a much more neglected topic. Most NEG contributions indeed heavily rely on restrictive assumptions about transportation. Transport costs are: (i) incurred in the good shipped itself (the so-called 'iceberg' assumption), which may be viewed as firms providing their own in-house transportation; (ii) symmetric irrespective of the shipping direction; and (iii) completely independent of the spatial organization of the economy (see, e.g., Krugman, 1991; Fujita et al., 1999; Ottaviano et al., 2002). From an economic point of view the most restrictive assumption is, however, that transport costs for goods are considered as being exogenenous parameters and not prices that are determined by the interplay of supply and demand. Put bluntly, NEG models focus overwhelmingly on the economic consequences of changes in an exogenous parameter whose value is completely independent from any price mechanism. Although such a simplifying assumption is a good starting point that has allowed to analyze more rigorously some 'old ideas' about spatial and regional development, it leaves a good deal of the story unexplained. How are transport costs determined by the market? How do they react to changes in supply and demand? What are the impacts of such changes on the spatial structure of the economy and, via feedback mechanisms, on transport costs themselves?

Just as growth theorists in the 1980s felt uncomfortable about explaining growth by appealing to some exogenous increase in productivity (the aspect you want to explain in the first place!), the same way spatial economists today should feel uncomfortable about explaining the spatial structure of the economy by simple changes in an exogenous parameter. The objective of this paper is therefore to partly open the black box of transport costs by endogenizing them through a competitive market mechanism. In our setting, competitive carriers provide transport services for shipping manufactured goods across regions, and freight rates (the prices for transportation) are determined endogenously to clear the transport markets. Each carrier commits to the maximum transport capacity for a round-trip and therefore faces a simple logistic problem: there are costs associated with 'returning empty'. ${ }^{1}$ The opportunity cost of transportation then depends on the direction of shipments. Consider, for instance, the case of a container ship that returns partly empty to its origin harbor. This ship has a very low (in fact a zero) opportunity cost for transporting additional goods in that direction and the carrier is, therefore,

\footnotetext{
${ }^{1}$ The problem of the "empties" is a very old one in transportation. Classic historical examples, where returning empty increased costs substantially, include the silk road trade betweem Asia and the West, as well as the 'triangular trade' betweem the UK, Africa and the Americas in the 18th century.
} 
enticed to undercut the price set by any fully loaded ship. The additional per unit costs incurred for a partly empty return trip increase the freight rates charged to manufacturing firms in the direction where there is excess demand for transport services. This simple mechanism has two important consequences. First, freight rates generally become asymmetric. Second, freight rates tend to increase where economic activity clusters into one region, thus creating a cost wedge in serving the different markets. This observation is key since two-region NEG models generally show that when regional asymmetries increase, firms have more incentives to save on transport costs by locating in the larger market. However, as we will show, this finding must be qualified in the presence of endogenous freight rates. The reason is that the larger region is also the larger exporter of manufactured goods, so that demand for transport services is higher there. In equilibrium, manufacturing firms in the larger region thus face higher freight rates, which reduces their incentives to stay in that region. Put differently, competitive pricing and logistic issues in transportation reduce agglomeration forces in the economy. It is worth stressing that investigating such imbalances in shipping goods, and the associated impacts on freight rates and prices, is not merely an academic exercise. Indeed, the growing imbalance of trade in manufactured goods between the U.S. (respectively Europe) and China is becoming a real issue for the transport sector and creates enormous logistic problems associated with the "empties". About $60 \%$ of the containers shipped from Asia to North America in 2005 came back empty, and those "that did come back full were often transported at a steep discount for lack of demand. [...] The cost of all this empty space on ships is a multibillion-dollar loss [...] an extra cost of doing business for the shipping companies, exporters and importers. [...] shipping companies charge an average of $\$ 1,400$ to transport a 20 -foot container from China to the United States. From the United States to China, the companies charge much less: $\$ 400$ or $\$ 500 . " 2$ To match that growing imbalance, the 11 members of the Transpacific Stabilization Agreement (TSA) recently agreed to raise their 2007-2008 freight rates from East Asia to the U.S. west coast by $\$ 300$ per 40 -foot container, pointing to "continuing import volumes at U.S. ports and a growing imbalance of cargo and equipment as reasons for the increases." 3 To sum up, the growing imbalance of trade between the U.S. and China is is reflected in the structure of USA-China freight rates and gives non-negligible incentives to US firms to use the empty container ships to send their product to China.

To analyze the effects of endogenous freight rates in detail, we incorporate a competitive transport sector into the two-region NEG model of Ottaviano et al. (2002) that embeds linear

\footnotetext{
${ }^{2}$ The figures and quotations are taken from the International Herald Tribune online edition (by T. Fuller, January 30, 2006; http://www.iht.com/articles/2006/01/29/business/ships.php?page=1). It is worth pointing out that the same phenomenon applies to air freight: "Airlines had become so eager to put something in their cargo holds on the inbound journey to China that rates go as low as 30 to 40 cents a kilogram, compared with $\$ 3$ to $\$ 3.50$ a kilogram leaving China."

${ }^{3}$ Taken from http://www.logisticstoday.com/displayStory.asp?sNO=8200
} 
transport costs. Carriers supply a homogenous transport service under constant returns to scale, which manufacturing firms have to pay for in terms of the economy's numeraire. The assumption of linear transport cost fits Hummels and Skiba's (2004) empirical finding that rejects iceberg, add-valorem transport costs. The assumption of a competitive transport market is not essential to our results. Indeed, the basic logistic problem created by trade imbalances between locations also exists in transport markets characterized by monopoly and oligopoly structures. The assumption of perfect competition nevertheless simplifies the analysis. ${ }^{4}$ In addition this assumption is justified by the observation that transport services in many industries are offered by numerous small agents (think, e.g., of the trucking industry). For instance, according to figures from the Bureau of Transport Statistics (BTS), ${ }^{5} 65 \%$ of the value added of the transport sector was due to trucking, which is nowadays commonly regarded as a quite competitive sector (at least in the wake of the Motor Carrier Act of 1980, which significantly deregulated the trucking industry). Finally we make the assumption that manufacturing firms outsource their transport services. According to BTS, transportation services in the U.S. accounted for $\$ 313$ billion, i.e. $5 \%$ of GDP, in 1992 . Of those $\$ 313$ billion, $\$ 192$ billion were generated by for-hire transportation. Although the in-house figure is quite substantial, it turns out that the manufacturing sector uses the largest share of for-hire transport services.

Our key findings may be summarized as follows. First, we show that a competitive transport sector significantly reduces the so-called 'home market effect' that is typically emphasized in the NEG literature. In particular, when transport costs become sufficiently small in the footloose capital model, exogenous freight rates lead to full agglomeration of firms in the larger region, whereas endogenous freight rates yield dispersion of firms with no home market bias. Second, we show in a core-periphery model that endogenous freight rates lead to multiple and different types of stable spatial equilibria. In particular, whereas only full agglomeration is a stable equilibrium under exogenous freight rates when physical transport costs are low, full agglomeration and full dispersion may simultaneously be stable equilibria under endogenous freight rates.

The remainder of the paper is organized as it follows. Section 2 presents the basic model and discusses the structure of the transport sector. Section 3 develops the footloose capital model and shows that endogenous freight rates are a strong dispersion force. Section 4 then extends the discussion to the core-periphery model and characterizes the spatial equilibria. Section 5 concludes and points towards future research directions.

\footnotetext{
${ }^{4}$ First, a monopoly transport firm would set a structure of freight rates that is similar to the competitive market: freight rates would be higher from locations that have largest trade and shipment volumes. Second, Bertrand price competition yields mixed strategy equilibria in the market for transport with trade imbalances. This structure of freight rates strongly complicates the analysis.

${ }^{5}$ See http://webbts.bts.gov/publications/transportation_statistics_newsletter/issue_04/entire.html
} 
Related literature. Despite the numerous technical difficulties associated with modeling transportation in general, several theoretical contributions provide a more detailed analysis of the impacts of transportation on the spatial structure of the economy than the standard NEG models do. Davis (1998), Fujita et al. (1999) and Picard and Zeng (2005) discuss the impacts of non-zero transport costs for agricultural goods. They show that positive transport costs in the agricultural sector reduce the likelihood of agglomeration through factor-price responses. Picard and Tabuchi (2003) and Behrens (2007) further show that the shape of the transport cost function (i.e., the relationship between distance and cost) influences the structure and the stability of spatial equilibria in continuous space. Takahashi (2006) discusses the impacts of both government spending on infrastructure and of the choice of transport technology on the agglomeration process. Behrens and Gaigné (2006) and Behrens et al. (2006) make transport costs depend on the spatial structure of the economy by considering the presence of transport density externalities. Finally, Behrens et al. (2007) investigate how the number of carriers operating in the market changes the spatial distibution of economic activity and how deregulation in the transport sector maps into consumer welfare changes.

Turning to the empirical side, economic research has provided quite detailed, but often contrasted, evidence on the impacts of a fall in transport costs on the spatial structure of economic activity (e.g., Combes and Lafourcade, 2005; Teixeira, 2006). To the best of our knowledge, this literature provides no detailed analysis of the structure of the transport sector, of its price-setting mechanisms, and of their impacts on the agglomeration of firms.

\section{Basic model}

Our model extends the NEG framework of Ottaviano et al. (2002) and Ottaviano and Thisse (2004) by endogenizing freight rates. Manufacturing firms first choose their location; transport firms then offer transport services to maximize profits and freight rates are determined to clear the transport market; and manufacturing firms finally set profit maximizing prices and product markets clear. We solve the model backwards starting with the product price equilibrium. We then characterize the transport market outcomes for any given spatial distribution of firms, and finally derive the spatial equilibrium distribution of mobile manufacturing firms.

\section{$2.1 \quad$ Preferences}

Consider a world with two regions labeled $i=H, F$. Variables associated with each region will be subscripted accordingly. We assume that there is a mass $L$ of consumers, a share $\theta_{H}$ of which is located in region $H$. In what follows we assume, without loss of generality, that $H$ is the larger region $\left(1 / 2 \leq \theta_{H}<1\right)$. All consumers have identical quasi-linear preferences over a homogeneous good and a unit mass of varieties of a horizontally differentiated good. The 
sub-utility over the varieties $v \in[0,1]$ of the manufactured good is quadratic. Preferences in region $i=H, F$ are then given as follows:

$$
U_{i} \equiv \alpha \int_{0}^{1} q_{i}(v) \mathrm{d} v-\frac{\beta-\gamma}{2} \int_{0}^{1}\left[q_{i}(v)\right]^{2} \mathrm{~d} v-\frac{\gamma}{2}\left[\int_{0}^{1} q_{i}(v) \mathrm{d} v\right]^{2}+q_{i}^{0},
$$

where $q_{i}(v)$ denotes the consumption of variety $v$; where $q_{i}^{0}$ stands for the consumption of the homogeneous good; and where $\alpha>0, \beta>\gamma>0$ are preference parameters.

Each consumer is endowed with $\bar{q}^{0}>0$ units of labor, which can be transformed into $\bar{q}^{0}$ units of the homogeneous good using a constant returns to scale technology. We assume that the homogeneous good can be costlessly traded between regions, which makes sure that its price is equalized across markets. Hence, we can choose it as the numéraire, i.e, $p_{i}^{0} \equiv p^{0}=1$. Each agent maximizes her utility (1) subject to her budget constraint

$$
\int_{0}^{1} p_{i}(v) q_{i}(v) \mathrm{d} v+q_{i}^{0} \leq w_{i}+\bar{q}^{0}
$$

where $p_{i}(v)$ stands for the consumer price of variety $v$ in region $i$; and where $w_{i}$ is the wage. As in Ottaviano et al. (2002), we assume that the labor endowment $\bar{q}^{0}$ is large enough for agents to consume the numéraire good in equilibrium, i.e., $q_{i}^{0}>0$. In that case, the demands for the varieties of the differentiated good include no income effects so that the allocation of firms' profits to shareholders and the location where these profits are generated are immaterial for the market outcome.

Maximizing (1) subject to (2) yields the following individual demands:

$$
q_{i}(v)=a-(b+c) p_{i}(v)+c \int_{0}^{1} p_{i}(v) \mathrm{d} v,
$$

where $a, b$ and $c$ are positive coefficients given by $a \equiv \alpha / \beta, b \equiv 1 / \beta$ and $c \equiv \gamma /[(\beta-\gamma) \beta]$.

In what follows, we assume that all manufacturig firms are symmetric and differ only by their location. This allows us to alleviate notation by dropping the variety index $v$. Let $p_{i j}$ stand for the consumer price of a variety produced in $i$ and sold in $j$. Assuming that the firm distribution across regions is given by $\left(n_{H}, n_{F}\right)$, aggregate demand for a variety produced in region $i$ and consumed in region $j$ is then given by

$$
Q_{i j} \equiv \theta_{j} L q_{i j}=\theta_{j} L\left[a-(b+c) p_{i j}+c \mathbb{P}_{j}\right]
$$

where $\mathbb{P}_{j} \equiv n_{j} p_{j j}+n_{i} p_{i j}$ denotes the price aggregate (the average price) in market $j=H, F$.

\subsection{Technology and product prices}

For the sake of simplicity, we assume that transportation is provided as a homogeneous service and that it takes the same amount of labor to ship each variety of the manufactured good. 
However, transport services are differentiated with respect to the shipping direction. Put otherwise, transport services from $H$ to $F$ and from $F$ to $H$ are different goods. Carriers offer services in each direction at unit freight rates $t_{H F}$ (from $H$ to $F$ ) and $t_{F H}$ (from $F$ to $H$ ) that will be determined within competitive transport markets. Since our focus is on analyzing how freight rates affect the spatial distribution of economic activity, we abstract from internal trade costs by assuming that transporting the good within each region is costless $\left(t_{H H}=t_{F F}=0\right)$. Because we assume that the transport market is perfectly competitive and that transportation is a homogeneous good in each direction, freight rates are independent of the chosen carrier. ${ }^{6}$

Production of each variety of the manufactured good incurs a constant marginal cost and a fixed cost $f$. Without loss of generality, we normalize the marginal cost to zero. ${ }^{7}$ The profit of a manufacturing firm established in region $i$ is given by

$$
\Pi_{i}=p_{i i} Q_{i i}+\left(p_{i j}-t_{i j}\right) Q_{i j}-f r_{i}, \quad i \neq j
$$

where $r_{i}$ stands for the returns to the fixed production factor. Note that (3) consists of the operating profits derived from local sales, the operating profits derived from distant sales ('exports'), minus the total payment $f r_{i}$ to the firm's fixed production factor. This fixed factor and its associated price can be interpreted as either entrepreneurs' time and earnings, or as skilled workers' time and wages, or as capital and capital rentals. We need not make a distinction between these interpretations for now, but we will come back to this point a bit later when distinguishing between the footloose entrepreneur and the core-periphery versions of the model.

Since each manufacturing firm is negligible to the market, it has no impact on the price indices $\mathbb{P}_{i}$, on the firm distribution $\left(n_{H}, n_{F}\right)$, and on the freight rates $t_{H F}$ and $t_{F H}$. Maximizing profits (3) with respect to prices yields a linear system of four first-order conditions. It is readily verified that the profit maximizing product prices and outputs in market $i$ are given by

$$
\begin{aligned}
p_{i i}\left(\mathbb{P}_{i}\right) & =\frac{1}{2} \frac{a+c \mathbb{P}_{i}}{b+c} \quad \text { and } \quad p_{j i}\left(\mathbb{P}_{i}\right)=p_{i i}\left(\mathbb{P}_{i}\right)+\frac{1}{2} t_{j i}, \quad i \neq j \\
q_{i i} & =(b+c) p_{i i} \quad \text { and } \quad q_{j i}=(b+c)\left(p_{j i}-t_{j i}\right), \quad i \neq j
\end{aligned}
$$

which depend on the price aggregates $\mathbb{P}_{H}$ and $\mathbb{P}_{F}$, themselves functions of the product prices. Solving for the fixed point, we readily obtain the equilibrium prices as follows:

$$
p_{i i}^{*}=\frac{1}{2} \frac{2 a+c n_{j} t_{j i}}{2 b+c} \quad \text { and } \quad p_{j i}^{*}=p_{i i}^{*}+\frac{t_{j i}}{2}, \quad i \neq j .
$$

\footnotetext{
${ }^{6}$ See Behrens et al. (2007) for the case of imperfectly competitive carriers producing a homogeneous transport service. Adding product differentiation in the transport sector, though relevant from an empirical point of view, would not materially change our main results.

${ }^{7}$ Introducing a constant marginal cost $m$ into the model is equivalent to rescaling the demand intercept $a /(b+c)$ to $a /(b+c)-m$ (see Ottaviano et al., 2002). As the choice of the parameters $a, b$ and $c$ is free, we can set $m=0$ without loss of generality.
} 
If we were to assume that $t_{H F}=t_{F H}=\tau$, expressions (4) would be identical to those in Ottaviano et al. (2002). The fundamental difference between their model and ours is that we consider that freight rates are: (i) not constant but determined by supply and demand in a competitive market; and (ii) not symmetric in both directions. As we will show, both of these aspects have profound impacts on the spatial distribution of firms and alter several standard results of basic NEG models.

To make sure that trade is always feasible and bilateral, i.e., $q_{H F}>0$ and $q_{F H}>0$ for any interregional allocation of firms, we impose the following trade feasibility condition on freight rates:

$$
\max \left\{t_{H F}, t_{F H}\right\}<\frac{2 a}{2 b+c} .
$$

In what follows, we assume that (7) always holds.

\subsection{Transportation and freight rates}

As argued in the introduction, an overwhelming share of manufacturing firms do not provide in-house transportation. Instead, they rely on for-hire transport services supplied by either privately owned and independent carriers (e.g., maritime freight, trucking, air freight), or by state-owned and regulated carriers (e.g., rail transportation). In the long run, many private carriers supply transport services under constant returns to scale, the building of fleet capacity being the most important fixed cost element for maritime freight. Regulated firms, by contrast, mostly supply transport services under increasing returns to scale. Because the latter usually stem from the cost of infrastructure, thereby yielding natural monopolies, many countries have separated the infrastructure management from the provision of transport services per se. As a result, those types of transport services are also supplied by a larger set of carriers, which has made the market far more competitive than in the past. In what follows, we therefore approximate the transport sector by a competitive industry. ${ }^{8}$

We start by analyzing the equilibrium of the transport sector for any given population distribution $\left(\theta_{H}, \theta_{F}\right)$ and any given firms distribution $\left(n_{H}, n_{F}\right)$. As mentioned in the foregoing, the freight rates in both directions are exogenously fixed at $\tau$ in Ottaviano et al. (2002). This case will provide a benchmark against which to judge the outcome when transportation is endogenously provided by competitive carriers.

We assume, without loss of generality, that one unit of transport service is required to ship one unit of manufacturing output. Furthermore, transport services are provided at constant marginal cost of $\tau$ units of the numéraire. The demand for transport services from $i$ to $j$, by a

\footnotetext{
${ }^{8}$ Note that maritime freight is clearly not a competitive sector because shipping cartels are tacitly allowed to collude on prices. Nevertheless, it is optimal for shipping cartels to set freight rates that differ according the direction of shipments when there exist export/import imbalances. It is this freight rate asymmetry that drives our results about the location of economic activity.
} 
manufacturing firm located in $i$, is then simply given by $Q_{i j} .{ }^{9}$ The total demand for transport service in this direction can be expressed as follows:

$$
D_{i j}\left(t_{i j}\right) \equiv n_{i} Q_{i j}=\frac{1}{2} L \theta_{j}\left[a+c \mathbb{P}_{j}-(b+c) t_{i j}\right] n_{i}, \quad i \neq j .
$$

As can be seen from expression (5), the demand for transport services naturally increases as the freight rate $t_{i j}$ falls. It also increases when region $i$ hosts more exporting firms (larger value of $n_{i}$ ) and when region $j$ has a larger population (larger value of $\theta_{j}$ ).

Each carrier provides transport services in both directions and faces a simple logistic problem: he must commit to the capacity required by the largest demand on a return trip. Put differently, the capacity required for the return trip is that in the direction of the largest demand for transport services. Carrier $k$ therefore earns the following profit:

$$
\Pi^{k} \equiv t_{H F} S_{H F}^{k}+t_{F H} S_{F H}^{k}-2 \tau \max \left\{S_{H F}^{k}, S_{F H}^{k}\right\}
$$

where $S_{H F}^{k}$ and $S_{F H}^{k}$ denote the supply of transport services from $i$ to $j$ and from $j$ to $i$, respectively; and where $2 \tau \max \left\{S_{H F}^{k}, S_{F H}^{k}\right\}$ stands for the cost of a return trip that the carrier must commit to. Note that transportation is always profitable for the carrier if $\max \left\{t_{H F}, t_{F H}\right\}<2 \tau$. A competitive equilibrium in the transport sector is given by non-negative freight rates $\left(t_{H F}, t_{F H}\right)$ and transport services $\left(\sum_{k} S_{H F}^{k}, \sum_{k} S_{F H}^{k}\right)$ such that: (i) carriers supply profit-maximizing quantities of transport service, taking freight rates, manufacturing prices, and the location of firms and consumers $\left(n_{i}\right.$ and $\left.\theta_{i}\right)$ as given; (ii) all carriers earn zero profits; and (iii) demand for transport services equals supply in each market $\left(D_{i j}=\sum_{k} S_{i j}^{k}\right) .{ }^{10}$

Given the profit (6), the carriers' supply depends on the equilibrium freight rates for a return trip. No carrier will supply any service if $t_{H F}+t_{F H}<2 \tau$. All carriers will supply an infinite amount of transport services if $t_{H F}+t_{F H}>2 \tau$. Last, they will supply any amount of transport services at $t_{H F}+t_{F H}=2 \tau$. In other words, transport firms supply a non-zero and finite quantity of transport service and earn zero profits if and only if the freight rates for a return trip equal its cost. A competitive equilibrium in the transport sector therefore exists in two cases (see Appendix A for technical details). In the first one, both transport markets clear at non-zero freight rates, i.e., $t_{H F}^{*}>0$ and $t_{F H}^{*}>0$. Because supplies are equal in each direction in such an equilibrium (a result that directly follows from the maximization of (6)), demands must also be equal in each direction: $S_{H F}^{k}=S_{F H}^{k} \Longleftrightarrow \sum_{k} S_{H F}^{k}=\sum_{k} S_{F H}^{k} \Longleftrightarrow$ $D_{H F}\left(t_{H F}^{*}\right)=D_{F H}\left(t_{F H}^{*}\right)$. A competitive equilibrium with non-zero freight rates therefore satisfies the following two conditions:

$$
D_{H F}\left(t_{H F}^{*}\right)=D_{F H}\left(t_{F H}^{*}\right) \quad \text { and } \quad t_{H F}^{*}+t_{F H}^{*}=2 \tau .
$$

\footnotetext{
${ }^{9}$ Alternatively, we could model transport services more explicitly as a matching process between carriers and manufacturers. Doing so makes the analysis more involved yet does not fundamentally change the forces at play (ships continue to return empty and freight rates are asymmetric).

${ }^{10}$ The assumption of constant returns to scale allows us to consider the transport sector as an aggregate.
} 
In the second case, one transport market clears at a non-zero price whereas the other market clears at a zero price with an excess supply of transport services. Suppose that $t_{H F}^{*}>0$ and that $t_{F H}^{*}=0$. In equilibrium, the freight rate $t_{H F}^{*}$ must be equal to the cost of a return trip, i.e., $t_{H F}^{*}=2 \tau$ for carriers to operate. The first market then clears when $\sum_{k} S_{H F}^{k}=$ $D_{H F}(2 \tau)$, whereas the second market has excess supply $\sum_{k} S_{F H}^{k} \geq D_{F H}(0)$. Such a competitive equilibrium obviously occurs if and only if $D_{H F}(2 \tau)>D_{F H}(0)$, i.e., if demands for transport services in the two directions become sufficiently asymmetric. ${ }^{11}$ Finally, given that the maximal transport cost is equal to $2 \tau$, the trade feasibility condition becomes

$$
\tau<\tau^{\text {trade }} \equiv \frac{a}{2 b+c}
$$

\subsection{Factor rents and spatial equilibrium}

We now turn to the location of manufacturing firms $\left(n_{H}, n_{F}\right)$ given the population distribution $\left(\theta_{H}, \theta_{F}\right)$ and the equilibrium freight rates $\left(t_{H F}^{*}, t_{F H}^{*}\right)$. Each manufacturing firm in country $i=H, F$ earns profits equal to

$$
\Pi_{i}=(b+c)\left[L \theta_{i} p_{i i}^{* 2}+L \theta_{j}\left(p_{i j}^{*}-t_{i j}^{*}\right)^{2}\right]-f r_{i}
$$

In equilibrium, these profits are absorbed by the factor rents, which implies that

$$
r_{i}^{*}=\frac{L(b+c)}{f}\left[\theta_{i} p_{i i}^{* 2}+\theta_{j}\left(p_{i j}^{*}-t_{i j}^{*}\right)^{2}\right] .
$$

It is convenient to define the 'access gain' from producing in market $i$ as follows:

$$
\begin{aligned}
R_{i}\left(t_{j i}^{*}\right) & \equiv \frac{L(b+c)}{f} \theta_{i}\left[p_{i i}^{* 2}-\left(p_{j i}^{*}-t_{j i}^{*}\right)^{2}\right] \\
& =\frac{L(b+c)}{f} t_{j i}^{*} \theta_{i} \frac{2 a-\left[4 b+c\left(2-n_{j}\right)\right] t_{j i}^{*}}{8(2 b+c)}, \quad i \neq j .
\end{aligned}
$$

Then, the factor rent differential across regions is simply equal to

$$
\Delta r^{*}=r_{H}^{*}-r_{F}^{*}=R_{H}\left(t_{F H}^{*}\right)-R_{F}\left(t_{H F}^{*}\right)
$$

This factor rent differential is positive when the access gain from producing in region $H$ exceeds that from producing in region $F$. A positive factor rent differential creates an incentive for factor owners to relocate their factors to region $H$, whereas a negative differential has the opposite effect. We define a spatial equilibrium to be a distribution of firms such that: (i) product and factor markets clear at the equilibrium prices $p_{i j}^{*}, t_{i j}^{*}$ and $r_{i}^{*}$ (for $i=H, F$ ); and (ii) no factor can fetch a higher return by changing location. Put differently, a spatial equilibrium is a scalar $n_{H}^{*}$ that satisfies one of the following three conditions: (i) $\Delta r^{*}=0$ with $n_{H}^{*} \in(0,1)$; or (ii)

\footnotetext{
${ }^{11}$ This can be seen as follows (see also Appendix A): $\sum_{k} S_{H F}^{k}=D_{H F}(2 \tau)>\sum_{k} S_{F H}^{k} \geq D_{F H}(0)$.
} 
$\Delta r^{*} \geq 0$ with $n_{H}^{*}=1$; or (iii) $\Delta r^{*} \leq 0$ with $n_{H}^{*}=0$. Case (i) will be referred to as an interior equilibrium, whereas cases (ii) and (iii) will be referred to as corner equilibria (agglomerated equilibria).

In what follows, we analyze two cases: the footloose capital model, where factor owners are immobile capitalists (see, e.g., Baldwin et al., 2003; Forslid and Ottaviano, 2003); and the core-periphery model, where factor owners are mobile skilled workers (see, e.g., Krugman, 1991; Ottaviano et al., 2002).

\section{Footloose capital model}

New trade and economic geography models in the wake of Krugman (1980) emphasize the fact that regional size asymmetries entice firms producing under increasing returns to scale to save on transport costs by locating close to their larger markets. In equilibrium, large countries host a share of firms in excess of their population share, an outcome termed the 'home market effect' (henceforth, HME; see, e.g., Helpman and Krugman, 1985). ${ }^{12}$ We now show that the presence of a competitive transport sector that faces logistic problems significantly qualifies this result. The intuition is that too much agglomeration is no longer feasible since it increases the freight rate differential across countries. Consequently, the HME gets strongly dampened so that a more even spatial equilibrium distribution of firms prevails. To guide intuition, we first briefly review the HME in a standard setting with exogenous and identical interregional transport costs. We then show that manufacturing firms are enticed to agglomerate less when freight rates are set by the market via a competitive transport sector. We finally show that the HME may entirely disappear when transport costs $\tau$ are sufficiently small.

In the remainder of this section, we assume that the market sizes are exogenously given by $\theta_{H} \geq \theta_{F} \equiv 1-\theta_{H}$. The resulting model without expenditure mobility is known as the 'footloose capital' model. In this type of model, the fixed factor $f$ can be interpreted as being capital used by manufacturing firms, and $r_{i}$ stands for the capital rents that are repatriated to their owners. The absence of income effects in our quasi-linear specification makes the actual distribution of profits across agents in each country irrelevant to the market outcome. We further assume, for simplicity, that workers in the transport sector are immobile and accounted for in the parameters $\left(\theta_{H}, \theta_{F}\right)$.

\subsection{Exogenous and identical freight rates}

This section derives the benchmark case with exogenous and identical freight rates, i.e., $t_{H F}=$ $t_{F H}=\tau$. Put differently, it corresponds to the special case where transport costs exactly equal

\footnotetext{
${ }^{12}$ The HME need not arise when there is no costlessly tradable good (Davis, 1998). In our framework, the HME always arises when transport costs are exogeneously given (Ottaviano and Thisse, 2004).
} 
half of the marginal cost of the return trip. The manufacturing prices, as given by (4), can be rewritten as:

$$
p_{i i}^{*}=\frac{1}{2} \frac{2 a+c n_{j} \tau}{2 b+c} \quad \text { and } \quad p_{j i}^{*}=p_{i i}^{*}+\frac{\tau}{2}, \quad \forall i \neq j .
$$

An (interior) spatial equilibrium can be determined from the condition that factor returns be equalized across countries, i.e.,

$$
\Delta r^{*}=R_{H}(\tau)-R_{F}(\tau)=\frac{L(b+c) \tau}{f}\left[\theta_{H}\left(p_{H H}^{*}-\frac{\tau}{4}\right)-\theta_{F}\left(p_{F F}^{*}-\frac{\tau}{4}\right)\right]=0
$$

Substituting the equilibrium prices (11), the foregoing expression can readily be solved to yield

$$
n_{H}^{*}=\left\{\begin{array}{crr}
\frac{1}{2}+\left(\theta_{H}-\frac{1}{2}\right) \frac{4 a-2 b \tau}{c \tau} & \text { if } \quad \begin{array}{r}
\theta_{H} \leq \bar{\theta}_{H} \\
1
\end{array} & \text { otherwise. }
\end{array}\right.
$$

In the foregoing expression,

$$
\bar{\theta}_{H} \equiv \frac{1}{2}+\frac{1}{2} \frac{c \tau}{4 a-2 b \tau}
$$

denotes the threshold regional size above which full agglomeration of all firms into the larger region obtains. Note that $(4 a-2 b \tau) /(c \tau)>1$ under the trade feasibility condition $\tau<\tau^{\text {trade }}$, which thereby establishes that $\bar{\theta}_{H} \in(0,1)$. The disproportionate location of industry in the larger region can then be easily seen by reshuffling the above expression to yield

$$
n_{H}^{*}-\frac{1}{2}=\underbrace{\frac{4 a-2 b \tau}{c \tau}}_{>1}\left(\theta_{H}-\frac{1}{2}\right) .
$$

In words, an increase in the size of a region maps into a more than proportionate increase in the mass of firms established there, which is precisely the HME. As shown by expression (14), the home market effect is 'magnified' for lower transport costs. In particular, when $\tau$ gets close to zero, the home market effect becomes so strong that full agglomeration occurs for any regional size asymmetries. We can summarize those results as follows.

Proposition 1 (Ottaviano and Thisse, 2004) Under exogenously given and identical freight rates, a home market effect always arises. This effect is magnified as transport costs fall, and firms fully agglomerate in the larger country for either small transport costs and/or large size asymmetries.

We now relax the admittedly strong assumption that freight rates are exogeneously given constants. As we will see, the foregoing properties are substantially modified in a setting where freight rates are endogenously determined in a competitive market. 


\subsection{Endogenous freight rates}

Assume now that freight rates are determined by the market clearing conditions for transportation services. We first characterize the case where freight rates are non-zero, i.e., when interregional shipments are balanced. Assume that $D_{H F}=D_{F H}$ which, as shown in Section 2.3, implies that $t_{H F}^{*}+t_{F H}^{*}=2 \tau, t_{H F}^{*}>0$ and $t_{F H}^{*}>0$. The equilibrium freight rate is given by

$$
t_{i j}^{*}=\frac{2\left[a\left(\theta_{i}-n_{i}\right)-\theta_{i}\left(1-n_{i}\right)\left(2 b+c n_{i}\right) \tau\right]}{2 b\left[n_{i}\left(2 \theta_{i}-1\right)-\theta_{i}\right]-c n_{i} n_{j}},
$$

which is feasible if and only if $0 \leq t_{i j}^{*} \leq 2 \tau$. One can readily verify that

$$
\lim _{n_{i} \rightarrow 0} t_{i j}^{*}=2 \tau-\frac{a}{b}<0 \quad \text { and } \quad \lim _{n_{i} \rightarrow 1} t_{i j}^{*}=\frac{a}{b}>2 \tau,
$$

where the inequalities derive from the trade feasibility condition $2 \tau<\tau_{\text {trade }}$ Expressions (16) show that configurations close to full agglomeration are never compatible with non-zero freight rates in both directions because there is excess capacity in at least one direction that cannot be absorbed by the market freight rates. Some cumbersome computations making use of the trade feasibility condition show that

$$
\frac{\partial t_{i j}^{*}}{\partial n_{i}}>0 \text { and } \quad \frac{\partial t_{i j}^{*}}{\partial \theta_{i}}<0
$$

As expected, the freight rate from $i$ to $j$ increases with the share of firms operating in region $i$ and with the size of region $j$. The intuition is that the larger region $i$ 's share of firms or the larger its trading partner $j$, the larger its share of production and exports. This results in an imbalance between the volumes of exports and imports, thereby putting strain on carriers that have to commit resources to return trips. The freight rates for exports from $i$ to $j$ thus must rise, which reduces region $i$ firms' competitiveness and exports; whereas the freight rates for imports from $j$ to $i$ must fall, which boosts regions $j$ firms' competitiveness and exports. When the imbalance gets too large (close to full agglomeration), the freight rates from the smaller to the larger country fall to zero, thus providing firms incentives to set up operations there.

We next analyze the impact of the transport sector on firms' location and on the HME. To begin with, we study the conditions under which full agglomeration may occur. When there is agglomeration in the larger region $H\left(1 / 2 \leq \theta_{H}<1\right.$ and $\left.n_{H}=1\right)$, we know from (16) that both freight rates cannot simultaneously be positive in that case. Therefore, the freight rate for shipping from the region with the small demand for transport services falls to zero, i.e., $t_{F H}^{*}=0<2 \tau=t_{H F}^{*}$. The incentives to locate in regions $H$ are then equal to

$$
\Delta r^{*}=R_{H}(0)-R_{F}(2 \tau)=-\frac{2 \tau L(b+c)(1-\theta)}{f}\left(p_{F F}^{*}-\frac{\tau}{2}\right)<0 .
$$

Put differently, full agglomeration is never an equilibrium for all $1 / 2 \leq \theta_{H}<1$. Because full agglomeration can never be an equilibrium under endogenous freight rates, we conclude that 
firms tend to disperse more in the presence of the transport sector and endogenous freight rates. To see this more clearly, assume that $1 / 2 \leq \theta_{H} \leq \bar{\theta}_{H}$ and fix the firm distribution to the interior equilibrium (13) obtained under exogenous freight rates. We then ask whether firms are enticed to disperse further if freight rates become endogenous. At an interior spatial equilibrium (13), the access gains from producing in each region are identical: $R_{H}(\tau)=R_{F}(\tau)$. Now observe that

$$
\frac{\mathrm{d} R_{i}}{\mathrm{~d} t_{j i}^{*}}=\frac{L(b+c)}{f} \theta_{i} \frac{a-\left(4 b+c\left(1+n_{i}\right)\right) t_{j i}^{*}}{4(2 b+c)}>0,
$$

where the inequality comes from the condition $\left.t_{j i}<2 \tau<2 a /\left(2 b+c n_{i}\right)\right)$ for all $0 \leq n_{i} \leq 1$. Therefore, when $t_{F H}^{*}<\tau<t_{H F}^{*}$, we see that $R_{H}\left(t_{F H}^{*}\right)<R_{H}(\tau)=R_{F}(\tau)<R_{F}\left(t_{H F}^{*}\right)$, which implies that $\Delta r^{*}<0$. Firms therefore unambiguously have an incentive to disperse more under endogenous freight rates when $1 / 2 \leq \theta_{H} \leq \bar{\theta}_{H}$.

Finally, we may investigate the location equilibrium when the transport $\operatorname{costs} \tau$ are close to zero. In this case, because $t_{H F}^{*}+t_{F H}^{*}=2 \tau$, both equilibrium freight rates $t_{H F}^{*}$ and $t_{F H}^{*}$ also tend to zero. The prices are approximately given by $a /(2 b+c)$, so that freight rates are of secondorder magnitude when compared to prices. As a result, expression (10) can be approximated to the first order by

$$
\Delta r^{*} \simeq \frac{L(b+c) a}{f(2 b+c)}\left(\theta_{H} t_{F H}^{*}-\theta_{F} t_{H F}^{*}\right) .
$$

The incentives to relocate to region $H$ simply depend on the difference between the transport bills $\theta_{i} L t_{j i}^{*}$ in both directions. The reason is that since freight rates are very small when compared to product prices, the latter ones are very similar in both markets. The factor rent differential then stems solely from the tiny difference between the transport bill when exporting to region $H$ or to regions $F .^{13}$ When freight rates are exogenous and identical in each direction, the transport bill is larger for exporting to the larger region $H$, which entices firms to produce in that region (to minimize transport costs). At the spatial equilibrium, firms fully agglomerate in region $H$ because $\Delta r^{*} \propto\left(\theta_{H}-\theta_{F}\right) \tau>0$. By contrast, when freight rates are endogenous this logic is significantly modified. Indeed, any interior spatial equilibrium is such that transport bills are equalized across countries: $t_{F H}^{*} \theta_{H}=t_{H F}^{*} \theta_{F}$. Asymmetries in market sizes and, therefore, in consumption shares are fully absorbed by freight rates. Plugging the freight rates (15) into (17), and approximating to the first order, we obtain the spatial equilibrium condition

$$
n_{H}^{*}-\frac{1}{2} \cong \theta_{H}-\frac{1}{2}
$$

Therefore, a rise in the population share yields a strictly proportional increase in the share of firms. Put differently, for small enough transport costs the HME disappears in the presence of

\footnotetext{
${ }^{13}$ It is worth noting that this results explains the apparently paradoxical fact that trade costs do seem to become more important in determining trade flows and the location of firms despite their continuing decline since about 50 years.
} 
endogeneous freight rates. We can summarize our results as follows.

Proposition 2 (Home market effect and endogenous freight rates) Under endogenous freight rates: (i) the home market effect is weaker than under exogenous freight rates; (ii) firms never fully agglomerate in the larger region; and (iii) the HME vanishes when transport costs are close to zero.

Unfortunately, we cannot analytically compute the spatial equilibrium by substituting product prices and freight rates into the relocation incentives $\Delta r^{*} \cdot{ }^{14}$ However, we can illustrate Proposition 2 with the help of a numerical example. Figure 1 depicts the spatial distribution $1 / 2 \leq n_{H}^{*} \leq 1$ of firms for transport costs $\tau$ ranging from 0 to $\tau^{\text {trade }}{ }^{15}$ The steeper curves on the left-hand side depict the firm distributions under exogenous and identical freight rates, whereas the flatter curves on the right-hand side depict the firm distributions under endogenous freight rates. For each case, the little arrows show how the the locus of spatial distribution moves as the transport cost $\tau$ increases. Figure 1 clearly illustrates our previous results: firms are more dispersed when freight rates are endogeneous and the HME vanishes with lower transport costs $\tau$.

\section{Insert Figure 1 about here.}

A final remark is in order. Indeed, one may wonder to what extent our results are driven by the assumption that the agricultural good can be transported at zero cost. What would happen in a world in which ships do not return "empty" but do bring back the (numeraire) agricultural good? First, as shown by Davis (1998) and Picard and Zeng (2005), introducing trade costs for the agricultural good constitutes an additional dispersion force which makes agglomeration less likely to occur. The reason is that factor price equalization no longer holds so that agglomeration raises wages and decreases firms' profitability in the agglomerating region. However, allowing for empty ships to carry agricultural goods relaxes the dispersion force in our model by narrowing the gap between the asymmetric freight rates. Yet, it is known that the bulk carrier fleets transporting agricultural goods are significantly different from the container carrier fleets transporting manufacturing goods. Therefore, there exist additional costs in transporting back agricultural goods on a fleet dedicated to manufacturing goods, which creates a trade cost wedge $t_{H F}-t_{F H}$ that works against agglomeration. ${ }^{16}$

\footnotetext{
${ }^{14}$ Doing so yields a polynomial of degree 7 with respect to $n_{H}$, which is impossible to analyze in detail.

${ }^{15}$ The parameter values are set as follows: $a=b=c=1$ and $f=.1$.

${ }^{16}$ As pointed out in the China-U.S. case: "The container imbalance between China and the West was to some extent a technical problem because China's main imports were bulk cargo - commodities like iron, soybeans and oil, which are not typically shipped in containers. This cargo is mismatched with China's exports, which are mostly manufactured goods." (International Herald Tribune, op. cit.)
} 
We now turn to the core-periphery model where firms co-locate with the owners of their production factors (Krugman, 1991; Ottaviano et al., 2002).

\section{Core-periphery model}

Assume, in what follows, that the population $L>1$ can be divided into entrepreneurs and workers. Entrepreneurs are the owners of the firms' fixed factors, and they are mobile across regions. They work in the manufacturing sector only. Workers, by contrast, are immobile and they work in either the constant returns or the transport sector. ${ }^{17}$ Because transport firms operate from both regions (they organize return trips), workers in the transport sector can reside in any region. However, those workers are paid the same unit wage whichever sector they work in. Therefore, their precise location is irrelevant to our analysis.

Following standard practice in core-periphery models, we assume that the immobile workers are evenly distributed across the two regions. For simplicity, we also assume that each firm needs one entrepreneur only, i.e., $f=1$. Since there is a unit mass of firms, there is then also a unit mass of entrepreneurs; the remaining $A \equiv(L-1) / 2$ agents are immobile workers in each region. All agents spend their income in the region they are located in. Hence, the mass of consumers in region $i=H, F$ is given by $\theta_{i} L=A+n_{i}$. Contrary to the footloose capital model, where factors are allocated across regions based on nominal rates of returns, entrepreneurs choose their locations in the core-periphery model based on indirect utility differentials between regions. This indirect utility is given by $V_{i} \equiv S_{i}+r_{i}$ (see Ottaviano et al., 2002), where

$$
S_{i}=\frac{a^{2}}{2 b}-a\left(n_{i} p_{i i}+n_{j} p_{j i}\right)-\frac{c}{2}\left(n_{i} p_{i i}+n_{j} p_{j i}\right)^{2}+\frac{(b+c)}{2}\left(n_{i} p_{i i}^{2}+n_{j} p_{j i}^{2}\right)
$$

stands for the consumer surplus and where $r_{i}$ is the return to entrepreneurship (the firm's profit, as given by (8)). ${ }^{18}$ The relocation incentives can now be expressed as follows:

$$
\Delta V^{*}=\Delta S^{*}+\Delta r^{*}=S_{H}^{*}-S_{F}^{*}+R_{H}^{*}-R_{F}^{*}
$$

A spatial equilibrium is a distribution $n_{H} \in[0,1]$ of entrepreneurs that satisfies one of the following three conditions: (i) $\Delta V^{*}=0$ with $n_{H} \in(0,1)$; or (ii) $\Delta V^{*} \geq 0$ with $n_{H}=1$; or (iii) $\Delta V^{*} \leq 0$ with $n_{H}=0$. Furthermore, an equilibrium distribution of entrepreneurs is said to be (asymptotically) stable if any small deviation from that distribution triggers an adjustment process that leads back to the initial equilibrium. In what follows, we consider the following

\footnotetext{
${ }^{17}$ When the marginal labor requirement in the manufacturing sector is not normalized to zero, this sector will draw workers from the constant returns sector. The results are qualitatively the same, provided there is enough labor so that the consumption of the numeraire remains positive for all agents.

${ }^{18}$ The notation $S_{i}$, standing for the consumer surplus in region $i$, should not to be confused with the earlier notation $S_{i j}^{k}$ which denotes the supply of transport service by carrier $k$ and which is no longer used in the sequel.
} 
law of motion for entrepreneurs:

$$
\frac{\mathrm{d} n_{H}}{\mathrm{~d} t}=\left\{\begin{array}{ccc}
\Delta V^{*} & \text { if } & n_{H} \in(0,1) \\
0 & \text { if } & n_{H}=0 \text { or if } n_{H}=1
\end{array}\right.
$$

Hence, an interior equilibrium distribution of entrepreneurs will be stable if moving to another region decreases their utility; whereas it will be unstable if moving to another region increases their utility.

As in the foregoing section, we first briefly review the properties of the traditional model with identical and exogenous freight rates. We then analyze in detail the more interesting case in which freight rates are endogeneously determined by a competitive transport market.

\subsection{Exogenous and identical freight rates}

In the model with exogenous and identical freight rates $\left(t_{H F}=t_{F H}=\tau\right)$ the consumer surplus differential, evaluated at the equilibrium prices (4), is given by

$$
\Delta S^{*}=S_{H}^{*}-S_{F}^{*}=\frac{(b+c)^{2}}{(2 b+c)^{2}}(2 a-\tau b) \tau\left(n_{H}-\frac{1}{2}\right),
$$

whereas the factor price differential (12) can be expressed as follows (recall that $f=1$ ):

$$
\Delta r^{*}=R_{H}^{*}(\tau)-R_{F}^{*}(\tau)=\frac{b+c}{2(2 b+c)} L \tau\left(n_{H}-\frac{1}{2}\right)[4 a-\tau(2 b+L c)] .
$$

Some standard calculations show that

$$
\Delta V^{*}=\kappa\left(n_{H}-\frac{1}{2}\right) \tau\left(\tau^{*}-\tau\right)
$$

where

$$
\tau^{*}=\frac{4 a(3 b+2 c)}{6 b^{2}+6 b c+c^{2}+2 A c(2 b+c)}
$$

and where $\kappa$ is a positive bundle of parameters independent of $\tau$. The foregoing expression reveals that $n_{H}=1 / 2$ is always a spatial equilibrium. Furthermore, $\left[\partial\left(\Delta V^{*}\right) / \partial n_{H}\right]_{n_{H}=1 / 2}<0$ for all values of $n_{H}$ if and only if $\tau>\tau^{*}$. In that case, starting from the symmetric distribution $n_{H}=1 / 2$, as more entrepreneurs move to region $H\left(n_{H}>1 / 2\right)$ their utility falls so that such a move is not profitable. By contrast, when $\tau<\tau^{*}$, as more entrepreneurs move to region $H$ $\left(n_{H}>1 / 2\right)$ their utility increases, which makes such a move profitable. Since the relocation incentives $\Delta V^{*}$ are positive for all $n_{H}>1 / 2$ when $\tau<\tau^{*}$, full agglomeration of all mobile entrepreneurs in region $H$ will be the equilibrium outcome. We may summarize these results as follows: 
Proposition 3 (Ottaviano et al., 2002) When $\tau>\tau^{*}$, dispersion $\left(n_{H}^{*}=1 / 2\right)$ is the only spatial equilibrium. When $\tau<\tau^{*}$, full agglomeration $\left(n_{H}^{*}=0\right.$ or $n_{H}^{*}=1$ ) of all mobile entrepreneurs into either region is the only stable equilibrium. In the special case where $\tau=\tau^{*}$, any distribution is an equilibrium.

Note that there exist sets of parameter values such that entrepreneurs fully agglomerate irrespective of the value of transport $\operatorname{costs} \tau,\left(\tau<\tau^{\text {trade }}\right)$. This happens when $\tau^{*} \geq \tau^{\text {trade }}$, a condition known as the 'black hole condition'.

\subsection{Endogenous freight rates}

We now show that, as in the footloose entrepreneur case, agglomeration patterns significantly differ when freight rates are determined in a competitive transport market. We first analyze and discuss the case of symmetric and fully agglomerated equilibria. As these are not the only outcomes under endogenous freight rates, we then analyze the case of partially agglomerated equilibria and present an example of the resulting firm distribution.

\subsubsection{Stable symmetric equilibria}

In what follows, let $[\cdot]_{n_{H}=1 / 2} \equiv[\cdot]_{1 / 2}$ to alleviate notation. The symmetric equilibrium is stable if and only if $\left[\partial\left(\Delta V^{*}\right) / \partial n_{H}\right]_{1 / 2}<0$. Note that in this model the price of a variety depends only on the number of local producers and on the freight rates of imports: $p_{H H}^{*}=p\left(n_{H}, t_{F H}\right)$ and $p_{F F}^{*}=p\left(n_{F}, t_{H F}\right)$. Since the access gain $R_{i}$ and the consumer surplus $S_{i}, i \in\{H, F\}$, depend only of the firm distribution and on the consumer prices, we can now use the definition $R_{i} \equiv R\left(n_{i}, t_{j i}\right)$ and $S_{i} \equiv S\left(n_{i}, t_{j i}\right)$. Because $n_{F} \equiv 1-n_{H}$, we have

$$
\left[\frac{\mathrm{d} \Delta V}{\mathrm{~d} n_{H}}\right]_{1 / 2}=2\left[\frac{\mathrm{d} R_{H}}{\mathrm{~d} n_{H}}\right]_{1 / 2}+2\left[\frac{\mathrm{d} S_{H}}{\mathrm{~d} n_{H}}\right]_{1 / 2} .
$$

A firm's gain from relocation is still given by (9), so that

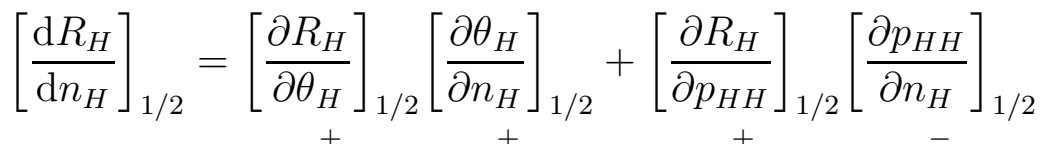

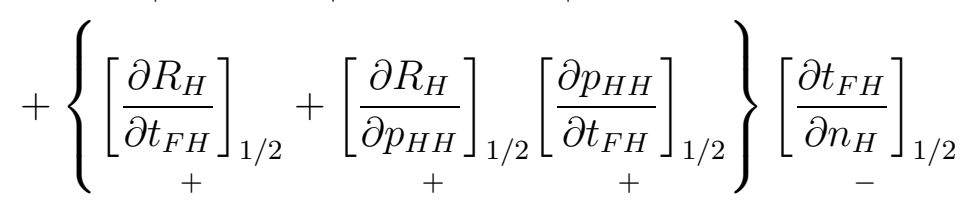


(see Appendix B for details on the signs of the derivatives). Turning to consumer surplus, it is readily verified that

$$
\begin{aligned}
{\left[\frac{\mathrm{d} S_{H}}{\mathrm{~d} n_{H}}\right]_{1 / 2} } & =\left[\frac{\partial S_{H}}{\partial n_{H}}\right]_{1 / 2}+\left[\frac{\partial S_{H}}{\partial p_{H H}}\right]_{1 / 2}\left[\frac{\partial p_{H H}}{\partial n_{H}}\right]_{1 / 2} \\
+ & \left\{\left[\frac{\partial S_{H}}{\partial t_{F H}}\right]_{1 / 2}+\left[\frac{\partial S_{H}}{\partial p_{H H}}\right]_{1 / 2}\left[\begin{array}{c}
\left.\frac{\partial p_{H H}}{\partial t_{F H}}\right]_{1 / 2} \\
-
\end{array}\right\}\left[\begin{array}{c}
\partial t_{F H} \\
\partial n_{H}
\end{array}\right]_{1 / 2}\right.
\end{aligned}
$$

(see Appendix B for details on the signs of the derivatives).

Several comments are in order. First, expression (18) captures the relocation incentives for entrepreneurs created by the returns to the fixed factor. Note that the first two terms in (18) hold irrespective of whether freight rates are endogenous or not. The first of these terms denotes the forward demand linkage: mobile entrepreneurs spend their income in the region they are established in, so that their relocation to region $H$ increases demand there, which in turn fosters agglomeration. The second term captures the competition effect: price competition is fiercer in the location where entrepreneurs agglomerate, which ceteris paribus entices them to disperse in order to soften competition. The last term of (18) is specific to our framework with endogenous freight rates. Since it is negative, it constitutes an additional dispersion force. As we have previously seen in the footloose capital model, an increase in region $H$ 's industry share increases freight rates in the direction of region $F$ and, thereby, reduces firms' incentives to locate in $H$. At the same time, lower freight rates in the direction of region $H$ increase the competitive advantage of firms located in $F$ which can now more easily serve customers in $H$. Competition intensifies in $H$, thus reducing the locational advantage of the larger region.

Second, while changes in factor rewards partly drive location decisions in the core-periphery model, mobile entrepreneurs also take into consideration changes in consumer surplus. Expression (19) captures these changes. The first two terms in (19) hold again irrespective of whether freight rates are endogenous or not. They show that entrepreneurs benefit from both a larger set of local varieties and from lower consumer prices caused by increased competition in the product market. The last term of (19) is specific to our framework with endogenous freight rates. Since it is positive, it constitutes an additional agglomeration force. Indeed, as more entrepreneurs and firms agglomerate in region $H$ the freight rates from region $F$ to $H$ decrease, thus putting downward pressure on the prices of imports (and, since goods are substitutes, also on prices of domestic goods). Put differently, when freight rates are endogenous the agglomeration of mobile entrepreneurs into one region puts additional downward pressure on prices in the larger region via changes in import freight rates. Whereas this is good news for entrepreneurs on the consumption side, it is bad news on the production side. The overall impact on agglomeration patterns is therefore a priori ambiguous and requires some more detailed investigation. 
We now compare the stability of the symmetric equilibrium under exogenous and endogenous freight rates. Note that because the first two terms in expressions (18) and (19) are exactly the same as under exogenous freight rates, by Proposition 3, their sum is positive if and only if $\tau<\tau^{*}$. Consequently, the agglomeration forces will be weaker under endogenous freight rates if and only if the sum of the last terms in (18) and (19) is negative. Standard computations show that the last terms of (18) and (19) are given by: ${ }^{19}$

$$
-\frac{4(b+c) L(a-b \tau)^{2}}{(2 b+c)(4 b+c)}<0 \quad \text { and } \quad \frac{(b+c)(a-b \tau)\left[8 a(b+c)-\tau\left(8 b^{2}+8 b c+c^{2}\right)\right]}{2(2 b+c)^{2}(4 b+c)}>0
$$

where the second inequality holds from the trade feasibility condition. Their sum can then be expressed as follows:

$$
\frac{(b+c)(a-b \tau)\left[-8 a((b+c)(L-1)+b L)-\left(c^{2}+8 b((b+c)(1-L)-b L)\right] \tau\right)}{2(2 b+c)^{2}(4 b+c)}
$$

As shown in Appendix $\mathrm{C}$, this expression is always negative for $0 \leq \tau \leq \tau^{\text {trade }} / 2$. We can therefore conclude that agglomeration forces are weaker and the stability of the symmetric equilibrium more likely under endogenous freight rates. In particular, it is obvious that firms will disperse under endogenous freight rates when $\tau=\tau^{*}$ since the sum of the two first terms in expressions (18) and (19) is zero, so that the negative term (20) dominates.

Although agglomeration forces are weaker when freight rates are endogenous than when they are exogenous, agglomeration may still be possible for some values of $\tau<\tau^{*}$. To check whether and when this case may arise, we sum all the terms in (18) and (19) to obtain:

$$
\left[\frac{\mathrm{d} \Delta V^{*}}{\mathrm{~d} n_{H}}\right]_{1 / 2} \propto-\Phi_{0}+\Phi_{1} \tau-\Phi_{2} \tau^{2}
$$

where

$$
\begin{aligned}
& \Phi_{0}=16 a^{2}[c(L-1)+b(2 L-1)]>0 \\
& \Phi_{1}=2 a\left[3 c^{2}+8 b^{2}(1+4 L)+2 b c(3+8 L)\right]>0 \\
& \Phi_{2}=c^{3} L+2 b c^{2}(1+3 L)+8 b^{3}(1+4 L)+6 b^{2} c(1+4 L)>0
\end{aligned}
$$

are three positive bundles of parameters. Hence, (21) is a concave and quadratic function of $\tau$, negative at $\tau=0$ and, by the foregoing arguments, also negative at $\tau^{*}$. We thus get the following proposition:

Proposition 4 (stability of the symmetric equilibrium) If $\Phi_{1}^{2}<4 \Phi_{2} \Phi_{0}$ the symmetric equilibrium is stable for all values of $\tau$; whereas if $\Phi_{1}^{2} \geq 4 \Phi_{2} \Phi_{0}$, there exist two thresholds $0<\tau_{1}<\tau_{2}<\tau^{*}$ such that the symmetric equilibrium is stable for $\left[0, \tau_{1}\right]$ and $\left[\tau_{2}, \tau^{\text {trade }}\right)$.

\footnotetext{
${ }^{19}$ Recall that $\theta_{H}=\left(A+2 n_{H}\right) /(2 L)=\left(L-1+2 n_{H}\right) /(2 L)$.
} 
Proposition 4 shows that, by contrast to the model with exogenous freight rates, symmetric equilibria are stable for transport $\operatorname{costs} \tau$ that are either close to zero or close to $\tau^{\text {trade }}$. Furthermore, there exist sets of parameters such that the symmetric equilibrium is stable for all values of $\tau$. Note that these results are analoguous to the ones in Puga (1999), where dispersion may also arise for both high and low values of trade costs. However, whereas the results require immobile labor in Puga's (1999) model, they are driven by the engogeneity of freight rates in our setting. Put differently, once freight rates are set by a competitive market, dispersion may be the equilibrium outcome even in the presence of very low transport costs when industry is a priori mobile across regions.

\subsubsection{Fully agglomerated equilibria}

Suppose now that firms fully agglomerate. Without loss of generality, we consider the case where $n_{H}=1$ and $n_{F}=0$. Note first that, as shown in Section 3.2., freight rates correspond in that case to the corner solution $t_{H F}^{*}=2 \tau$ and $t_{F H}^{*}=0$. This is because an interior solution for freight rates would yield $t_{F H}^{*}=2 \tau-a / b$, which is negative for all admissible values of $\tau<\tau^{\text {trade }}$. Consequently, freight rates from $H$ to $F$ do no longer rise with further agglomeration of firms in the neighborhood of full agglomeration. Put differently, once agglomeration is strong enough transport markets no longer work to reduce agglomeration forces. Although freight rates then become exogenous, as in Ottaviano et al. (2002), they take different values depending on the direction of shipments. In particular, because of the absence of firms in region $F$, carriers return empty to region $H$, so that the opportunity cost of the return trip is zero: $t_{F H}^{*}=0$. As a result manufacturing firms face no competitive disadvantage in serving the larger core market $H$ from the smaller peripheral market $F$. The role of the transport sector is, therefore, quite similar to that of an asymmetric import tariff that would protect region $F$.

Under full agglomeration in region $H$, consumer prices are given by $p_{H H}^{*}=a /(2 b+c)$ and $p_{F F}^{*}=(a+2 c \tau) /(2 b+c)$. The factor price and consumer surplus differentials can then be expressed as follows:

$$
\left[\Delta r^{*}\right]_{1}=-\frac{(b+c)(L-1) \tau[2(a-b \tau)+c \tau]}{2(2 b+c)}<0
$$

and

$$
\left[\Delta S^{*}\right]_{1}=\frac{2(b+c)^{2} \tau(a-b \tau)}{(2 b+c)^{2}}>0 .
$$

The foregoing expressions show that, on the one hand, entrepreneurs earn more if they relocate to the smaller market $F$. This is because they can serve the remote region without being harmed by competition there, whereas they are able to ship their products at zero costs to the larger market $H$. Recalling that $A \equiv L-1$, we see that this effect is stronger when the local immobile demand $A$ is large. On the other hand, since entrepreneurs are also consumers, 
they prefer to locate in the larger region $H$ as consumer prices are lower there. Contrary to the foregoing effect through factor rents, the consumer surplus effect does not depend on the demand size $A$. Adding the factor price and the consumer surplus effects, we obtain the indirect utility effect as follows:

$$
\left[\Delta V^{*}\right]_{1}=\frac{\tau(b+c)}{2 b+c}\left[\frac{2(b+c)(a-b \tau)}{2 b+c}-(L-1) \frac{2(a-b \tau)+c \tau}{2}\right]
$$

where both terms in the brackets are positive because of the trade feasibility condition. Hence, full agglomeration is an equilibrium, if and only if $\left[\Delta V^{*}\right]_{1}>0$, i.e.,

$$
A<G(\tau) \equiv \frac{4(b+c)(a-\tau b)}{(2 b+c)[2(a-b \tau)+c \tau]}<4
$$

where $G(\tau)$ is positive and decreases with $\tau$. In words, full agglomeration can occur only if local immobile demand $A$ is small enough. Because $G(\tau)$ decreases in $\tau$, full agglomeration is an equilibrium for all $\tau \in\left(0, \tau^{\text {trade }}\right]$ if $A<G\left(\tau^{\text {trade }}\right)$. It is never an equilibrium if $A>G(0)$. Otherwise it is an equilibrium if $\tau<G^{-1}(A)$. These findings may be summarized as follows:

Proposition 5 (fully agglomerated equilibrium) Full agglomeration in region $H$ is a stable equilibrium for all admissible values of $\tau$ if $A<4(b+c)^{2} /[(2 b+3 c)(2 b+c)]$. It is never a stable equilibrium if $A>2(b+c) /(2 b+c)$. Otherwise it is a stable equilibrium if $\tau<\widehat{\tau} \equiv 2 a[2(b+c)-A(2 b+c)] /\left[2 b(b+c)-A\left(4 b^{2}-c^{2}\right)\right]$.

Proposition 5 shows that, in the case of full agglomeration, the traditional conclusions obtained under exogenous and identical freight rates carry through to the setting with endogenous freight rates. Indeed, even under endogenous freight rates full agglomeration is never an equilibrium for a large enough immobile population $A$. This is because the positive effect of locating in the smaller market $F$ dominates the negative effect of higher consumer prices. Entrepreneurs find it more profitable to locate in the smaller region so that they can serve it without being harmed by competition, shipping their products at no competitive disadvantage to the larger region. This competitive advantage largely compensates for the higher prices they must pay for their consumption in the smaller region.

Furthermore, it is worth noting that when the immobile population $A$ is small enough, there exist multiple stable equilibria where both dispersion and full agglomeration coexist. Dispersion occurs because the transport sector reduces agglomeration forces as entrepreneurs in the larger region pay higher transport costs and refrain from agglomerating. Full agglomeration case arises because the transport market is saturated in one direction so that the freight rates are set to their maximal and minimal values irrespectively of firms' location. The transport sector then no longer contributes to a reduction in agglomeration forces, i.e., agglomeration becomes profitable for entrepreneurs who are able to ship their goods at a fixed price and to consume at lower prices. 


\subsubsection{Other stable interior equilibria}

Unfortunately, it is not possible to provide a detailed characterization of the interior spatial equilibria of the model as they involve solving a higher-order polynomial equation in $n_{H}$. To make the analysis even more involved, the trade feasibility condition depends on the (interior equilibrium) spatial distribution $n_{H}^{*}$, which depends itself on the values of $t_{H F}$ and $t_{F H}$. Restricting the analysis to symmetric and interior equilibria only, it is however possible to obtain additional insights by considering numerical examples. Figure 2 plots the zero utility differential isocurve $\Delta V$ in $\left(\tau, n_{H}\right)$-space for $\tau$ varying between 0 and $\tau^{\text {trade }}{ }^{20}$ The bold lines correspond to stable location equilibria while dashes lines correspond to unstable equilibria. The arrows indicate the direction of $\mathrm{d}(\Delta V) / \mathrm{d} t$, i.e., the relocation process that takes place after small perturbations of the equilibrium.

\section{Insert Figure 2 about here.}

As one can see from Figure 2, full agglomeration is always an equilibrium whereas symmetric dispersion is a stable equilibrium only for values of trade costs $\tau$ smaller than $0.15 .^{21}$ In addition, there exist asymmetric interior equilibria for $\tau \in[0.15,0.20]$. It is worth pointing out that under endogenous freight rates one of the key results of economic geography gets reversed: partial agglomeration decreases as trade costs fall, and in the end dispersion may prevail for low trade costs. The reason is that dispersion makes trade costs more symmetric, thus favoring a more balanced spatial pattern.

It is also worth pointing out that changes in freight rates with the spatial distribution of firms are key to understanding why dispersion (resp., partial agglomeration) and full agglomeration

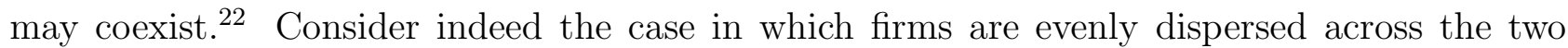
regions. More agglomeration in region $H$ then has several effects. First, it increases local market size and offers consumers cheaper local access to varieties produced in $H$. Since at the same time freight rates from $F$ to $H$ fall, imports also become cheaper. When taken together, this consumer surplus effect constitutes a stronger agglomeration force than in the model with exogeneous freight rates and may explain why full agglomeration can be stable for all values of $\tau$. At the same time, the positive consumer surplus effect is balanced by a negative rental rate effect. Indeed, agglomeration raises freight rates from $H$ to $F$, thus making access to the foreign market more expensive. This constitutes a dispersion force that becomes dominant when the foreign market is large enough. In particular, assume that dispersion prevails. Then the increase in freight rates $t_{H F}$, and the associated increase in the costs of serving $F$ from $H$,

\footnotetext{
${ }^{20}$ The underlying parameter values are as follows: $a=b=c=1$ and $A=0.3$

${ }^{21}$ Note that the existence of full agglomeration for all values of transport costs is not violating the "no-blackhole condition' because other stable equilibria coexist. The 'no-black-hole condition' states that the economy fully agglomerates for all values of transport costs and that full agglomeration is the only spatial equilibrium.

${ }^{22}$ See also Behrens and Gaigné (2006) and Behrens et al. (2006) for a similar finding when there are exogeneously given density economies in transportation.
} 
may make a relocation from $F$ to $H$ unprofitable since it decreases profits and the returns to the mobile factor. Put differently, the positive consumer surplus effect is more than offset by the negative freight rate effect so that dispersion is a stable spatial equilibrium.

\section{Conclusion}

The present paper offers novel contribution about the limits of the new economic geography paradigm (Krugman 1991). The issue of transport costs in this literature is not a new one. A decade ago, Davis (1998) and Fujita et al. (1999) have already emphasized the important consequences of the 'simplifying' assumption of zero transport costs for agricultural varieties. Picard and Tabuchi (2008) have also discussed the role of the shape of transport cost for manufacturing goods on the spatial distribution of the economic activity. This paper emphasizes the important consequence of another assumption. This is about the logistic nature of transport sector in the simple two-region model that is usually discussed. A particularity of the transport sector is that carriers must commit to capacities and offer transport services in both directions of trade. Because of the logistic problem of the "empties", imbalances in the volume of trade map into freight rate differentials that favor a more balanced distribution of economic activity.

The paper shows that the traditional agglomeration forces can be substantially dampened by the transport firms because their freight rates endogenously respond to trade and shipment imbalances. As a result, asymmetries in market sizes and therefore in consumption shares can be partly or fully absorbed by freight rates. We have shown in the footloose capital model that the home market effect is significantly attenuated by the presence of a competitive transport sector. Furthermore, in the core-periphery model the distribution of firms can also be strongly altered by the presence of such a transport sector. The impact of the transport sector can be so strong that manufacturing firms may have incentives to evenly disperse under endogenous freight rates in the same economic parameters as those for which they have incentives to agglomerate under the exogenous freight rates. Such results tone down the predictions about economic agglomeration and their corresponding policy recommendations that are presented in the traditional new economic literature. In particular, our analysis suggests that the bad consequences of globalization (as a fall of trade costs) on regional disparities might be overemphasized. In any case, the present paper opens the interesting empirical question about the effect of freight rates on trade imbalances and firms location, a question that is left for future research. 
[1] Baldwin, R.E. and T. Okubo (2006) Heterogeneous firms, agglomeration and economic geography: spatial selection and sorting, Journal of Economic Geography 6, 323-346.

[2] Behrens, K. (2007) On the location and lock-in of cities: geography vs transportation technology, Regional Science and Urban Economics 37, 22-45.

[3] Behrens, K. and C. Gaigné (2006) Density economies in transportation: revisiting the core-periphery model, Economics Bulletin 18, 1-7.

[4] Behrens, K., C. Gaigné, G.I.P. Ottaviano and J.-F. Thisse (2006) How density economies in international transportation link the internal geography of trading partners, Journal of Urban Economics 60, 248-263.

[5] Behrens, K., C. Gaigné and J.-F. Thisse (2007) Is regulating of transport sector always detrimental to consumers? CEPR Discussion Paper \#6185.

[6] Combes, P.-Ph. and M. Lafourcade (2005) Transport costs: measures, determinants, and regional policy implications for France, Journal of Economic Geography 5, 319-49.

[7] Davis, D. (1998) The home market, trade, and industrial structure, American Economic Review 88, 1264-1276.

[8] Forslid, R. and G.I.P. Ottaviano (2003) An analytically solvable core-periphery model, Journal of Economic Geography 3, 229-240.

[9] Fujita, M., P.R. Krugman and A.J. Venables (1999) The Spatial Economy: Cities, Regions and International Trade. Cambridge (Mass.): MIT Press.

[10] Helpman, E. and P.R. Krugman (1985) Market Structure and Foreign Trade. Cambridge, MA: MIT Press.

[11] Hummels, D. and Skiba A. (2004) Shipping the Good Apples Out? An Empirical Confirmation of the Alchian-Allen Conjecture. Journal of Political Economy 112(6), 1384-1402.

[12] Krugman, P.R. (1980) Scale economies, product differentiation and the pattern of trade, American Economic Review 70, 950-959.

[13] Krugman, P.R. (1991) Increasing returns and economic geography, Journal of Political Economy 99, 483-499.

[14] Ottaviano, G.I.P., T. Tabuchi and J.-F. Thisse (2002) Agglomeration and trade revisited, International Economic Review 43, 409-436. 
[15] Ottaviano, G.I.P. and J.-F. Thisse (2004) Agglomeration and economic geography. In: Handbook of Regional and Urban Economics, vol. 4, J.V. Henderson and J.-F. Thisse (eds.). Amsterdam: North-Holland, 2564-2608.

[16] Picard, P.M. and T. Tabuchi (2008) Self-organized Agglomerations and Transport Costs. Forthcoming in Economic Theory.

[17] Puga, D. (1999) The rise and fall of regional inequalities, European Economic Review 43, 303-334.

[18] Picard, P.M. and D.-Z. Zeng (2005) Agricultural sector and industrial agglomeration, Journal of Development Economics 77, 75-106.

[19] Takahashi, T. (2006) Economic geography and endogenous determination of transport technology, Journal of Urban Economics 60, 498-518.

[20] Teixeira, A.C. (2006) Transport policies in light of the new economic geography: The Portuguese experience, Regional Science and Urban Economics 36, 450-466.

\section{Appendix A: Carriers' profit maximization}

Each carrier maximizes its profits with respect to its output:

$$
\max _{S_{i j}^{k}, S_{j i}^{k}} \Pi^{k}=t_{i j} S_{i j}^{k}+t_{j i} S_{j i}^{k}-2 \tau \max \left\{S_{i j}^{k}, S_{j i}^{k}\right\}
$$

Without loss of generality, we assume that region $i$ has the larger demand for transport services, which then implies that $S_{i j}^{k} \geq S_{j i}^{k}$. Two cases may arise:

1. $S_{i j}^{k}>S_{j i}^{k}$.

In that case, the problem reduces to

$$
\max _{S_{i j}^{k}, S_{j i}^{k}} \Pi^{k}=\left(t_{i j}-2 \tau\right) S_{i j}^{k}+t_{j i} S_{j i}^{k}
$$

which implies that the carrier: (i) does not offer any service from $i$ to $j$ when $t_{i j}<2 \tau$; (ii) does provides an infinite amount of service from $i$ to $j$ when $t_{i j}>2 \tau$, and an infinite amount from $j$ to $i$ when $t_{j i}>0$; and (iii) does provides a positive and finite marketclearing quantity and earns zero profits when $t_{i j}=2 \tau$ and $t_{j i}=0$.

2. $S_{i j}^{k}=S_{j i}^{k}$. 
The first-order conditions (in vector notation) are given by

$$
\left(\begin{array}{c}
t_{i j} \\
t_{j i}
\end{array}\right)-2 \tau \xi=0, \text { where } \xi \in\left\{\delta\left(\begin{array}{l}
1 \\
0
\end{array}\right)+(1-\delta)\left(\begin{array}{l}
0 \\
1
\end{array}\right), 0<\delta<1\right\}
$$

Put differently, $t_{i j}=2 \tau \delta>0$ and $t_{j i}=2 \tau(1-\delta)>0$. Note that the value of $\delta$, which pins down the equilibrium freight rates, will be endogeneously determined by the market clearing conditions.

\section{Appendix B: Stability of the symmetric core-periphery equilibrium}

B.1. Comparative statics for freight rates We can readily establish the comparative statics of freight rates with respect to market size $\theta_{i}$ and industry location $n_{i}$ at the symmetric equilibrium as follows:

$$
\frac{\partial t_{H F}}{\partial n_{H}}=-\frac{\partial t_{H F}}{\partial n_{F}}=\frac{8(a-\tau b)}{4 b+c}>0, \quad \frac{\partial t_{H F}}{\partial \theta_{H}}=-\frac{\partial t_{H F}}{\partial \theta_{F}}=2 \tau-\frac{8 a}{4 b+c}<0
$$

and

$$
\frac{\mathrm{d} t_{H F}}{\mathrm{~d} n_{H}}=-\frac{\mathrm{d} t_{F H}}{\mathrm{~d} n_{H}}=\frac{2[4(a-b \tau)+c \tau]}{(4 b+c) L}>0
$$

B.2. Expressions for the stability of the symmetric equilibrium We give the expressions of the derivatives used to analyze the stability of the symmetric equilibrium of the core-periphery model with endogenous freight rates. Note first that

$$
\left[t_{F H}\right]_{1 / 2}=\left[t_{H F}\right]_{1 / 2}=\tau, \quad \text { so that } \quad\left[p_{H H}\right]_{1 / 2}=\left[p_{F F}\right]_{1 / 2}=p=\frac{2 a+c(\tau / 2)}{2(2 b+c)}
$$

and that

$$
\left[\frac{\partial p_{H H}}{\partial t_{F H}}\right]_{1 / 2}=\frac{c}{4(2 b+c)}>0, \quad\left[\frac{\partial p_{H H}}{\partial n_{H}}\right]_{1 / 2}=-\frac{c \tau}{2(2 b+c)}<0 .
$$

Turning next to the impacts of firms' location on market size, we obviously have

$$
\left[\frac{\partial \theta_{H}}{\partial n_{H}}\right]_{1 / 2}=1
$$

Concerning the relocation incentives, we obtain the following derivatives:

$$
\left[\frac{\partial R_{H}}{\partial p_{H H}}\right]_{1 / 2}=\frac{(b+c) \tau}{2}>0, \quad\left[\frac{\partial R_{H}}{\partial t_{F H}}\right]_{1 / 2}=\frac{(b+c)[4 a-(4 b+c) \tau]}{8(2 b+c)}>0
$$

and

$$
\left[\frac{\partial R_{H}}{\partial \theta_{H}}\right]_{1 / 2}=\frac{(2 a-b \tau)(b+c) \tau}{2(2 b+c)}>0
$$


where the second inequality comes from the trade feasibility condition.

Turning finally to the consumer surplus, we obtain the following derivatives:

$$
\left[\frac{\partial S_{H}}{\partial n_{H}}\right]_{1 / 2}=\frac{(2 a-b \tau)(b+c) \tau}{4(2 b+c)}>0 \quad\left[\frac{\partial S_{H}}{\partial p_{H H}}\right]_{1 / 2}=-\frac{(b+c)(2 a-b \tau)}{2(2 b+c)}<0
$$

and

$$
\left[\frac{\partial S_{H}}{\partial t_{F H}}\right]_{1 / 2}=-\frac{(b+c)[4(a-b \tau)+c \tau]}{16(2 b+c)}<0
$$

\section{Appendix C: Additional dispersion force}

In this appendix, we show that expression (20) is always negative. First, note that (20) at $\tau=0$ is given by

$$
-\frac{4 a^{2}(b+c)[(b+c)(L-1)+b L]}{(2 b+c)^{2}(4 b+c)}<0
$$

Since it is a linear expression with respect to $\tau$, it is enough to check its sign for $\tau=\tau^{\text {trade }} / 2$. The corresponding expression is given by

$$
\frac{a^{2}(b+c)^{2}\left(8 b^{2}+16 b c+7 c^{2}-8(b+c)(2 b+c) L\right)}{2(2 b+c)^{4}(4 b+c)},
$$

which is decreasing in $L$. Since $L>1$, and since this expression is negative for $L=1$, it is always negative. This establishes our claim. 


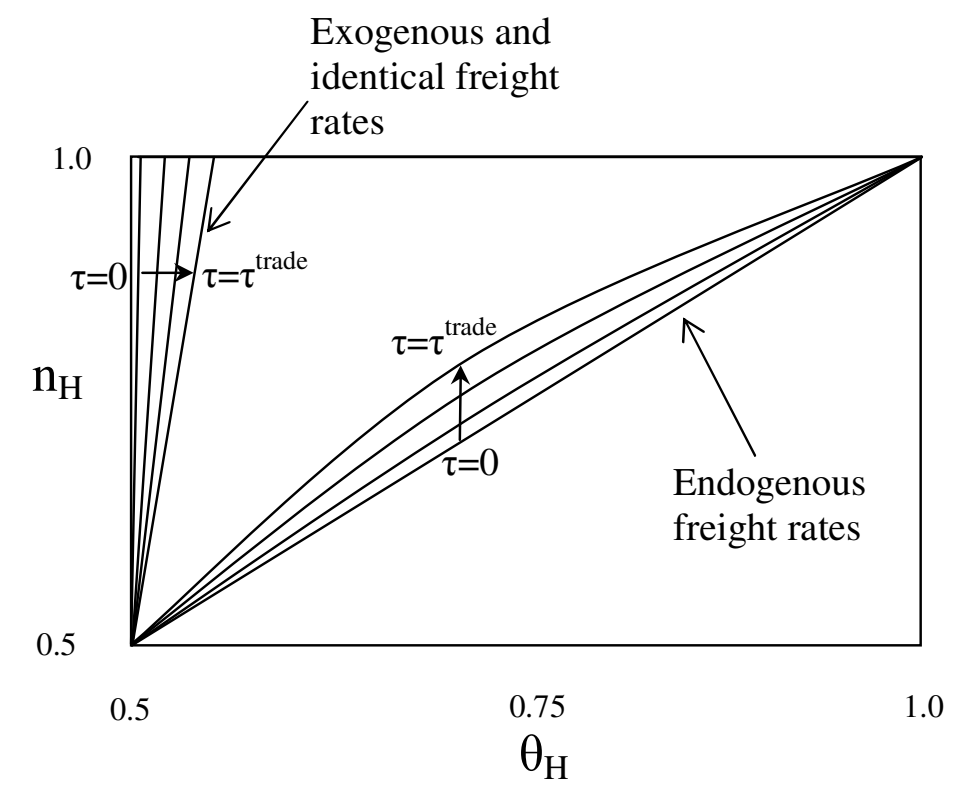

Figure 1: Location equilibrium in footloose capital model. 


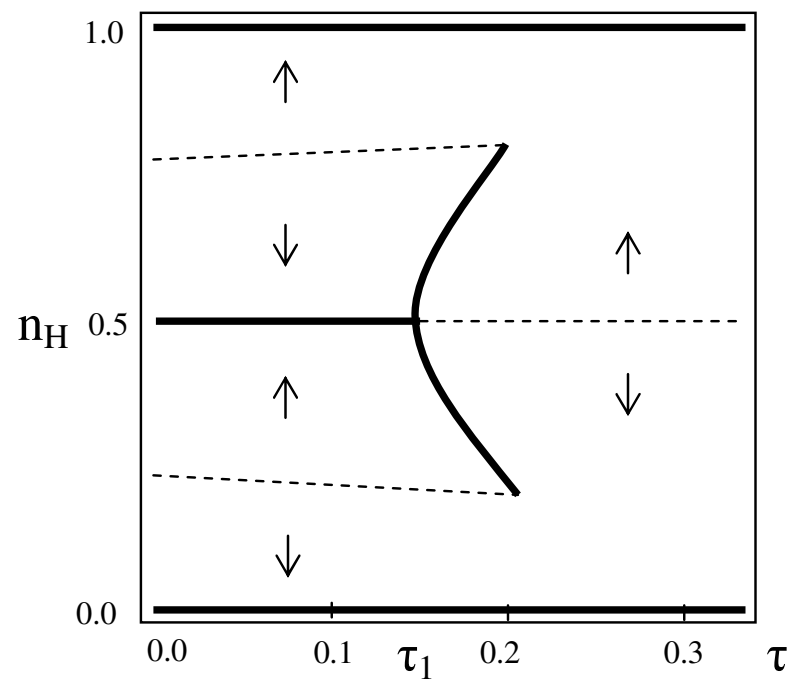

Figure 2: Location equilibria in core-periphery model. 


\section{Recent titles \\ CORE Discussion Papers}

2008/2. Oscar AMERIGHI and Giuseppe DE FEO. Privatization and policy competition for FDI.

2008/3. Wlodzimierz SZWARC. On cycling in the simplex method of the Transportation Problem.

2008/4. John-John D'ARGENSIO and Frédéric LAURIN. The real estate risk premium: A developed/emerging country panel data analysis.

2008/5. Giuseppe DE FEO. Efficiency gains and mergers.

2008/6. Gabriella MURATORE. Equilibria in markets with non-convexities and a solution to the missing money phenomenon in energy markets.

2008/7. Andreas EHRENMANN and Yves SMEERS. Energy only, capacity market and security of supply. A stochastic equilibrium analysis.

2008/8. Géraldine STRACK and Yves POCHET. An integrated model for warehouse and inventory planning.

2008/9. Yves SMEERS. Gas models and three difficult objectives.

2008/10. Pierre DEHEZ and Daniela TELLONE. Data games. Sharing public goods with exclusion.

2008/11. Pierre PESTIEAU and Uri POSSEN. Prodigality and myopia. Two rationales for social security.

2008/12. Tim COELLI, Mathieu LEFEBVRE and Pierre PESTIEAU. Social protection performance in the European Union: comparison and convergence.

2008/13. Loran CHOLLETE, Andréas HEINEN and Alfonso VALDESOGO. Modeling international financial returns with a multivariate regime switching copula.

2008/14. Filomena GARCIA and Cecilia VERGARI. Compatibility choice in vertically differentiated technologies.

2008/15. Juan D. MORENO-TERNERO. Interdependent preferences in the design of equal-opportunity policies.

2008/16. Ana MAULEON, Vincent VANNETELBOSCH and Wouter VERGOTE. Von NeumannMorgenstern farsightedly stable sets in two-sided matching.

2008/17. Tanguy ISAAC. Information revelation in markets with pairwise meetings: complete information revelation in dynamic analysis.

2008/18. Juan D. MORENO-TERNERO and John E. ROEMER. Axiomatic resource allocation for heterogeneous agents.

2008/19. Carlo CAPUANO and Giuseppe DE FEO. Mixed duopoly, privatization and the shadow cost of public funds.

2008/20. Helmuth CREMER, Philippe DE DONDER, Dario MALDONADO and Pierre PESTIEAU. Forced saving, redistribution and nonlinear social security schemes.

2008/21. Philippe CHEVALIER and Jean-Christophe VAN DEN SCHRIECK. Approximating multiple class queueing models with loss models.

2008/22. Pierre PESTIEAU and Uri M. POSSEN. Interaction of defined benefit pension plans and social security.

2008/23. Marco MARINUCCI. Optimal ownership in joint ventures with contributions of asymmetric partners.

2008/24. Raouf BOUCEKKINE, Natali HRITONENKO and Yuri YATSENKO. Optimal firm behavior under environmental constraints.

2008/25. Ana MAULEON, Vincent VANNETELBOSCH and Cecilia VERGARI. Market integration in network industries.

2008/26. Leonidas C. KOUTSOUGERAS and Nicholas ZIROS. Decentralization of the core through Nash equilibrium.

2008/27. Jean J. GABSZEWICZ, Didier LAUSSEL and Ornella TAROLA. To acquire, or to compete? An entry dilemma.

2008/28. Jean-Sébastien TRANCREZ, Philippe CHEVALIER and Pierre SEMAL. Probability masses fitting in the analysis of manufacturing flow lines.

2008/29. Marie-Louise LEROUX. Endogenous differential mortality, non monitored effort and optimal non linear taxation. 


\section{Recent titles}

\section{CORE Discussion Papers - continued}

2008/30. Santanu S. DEY and Laurence A. WOLSEY. Two row mixed integer cuts via lifting.

2008/31. Helmuth CREMER, Philippe DE DONDER, Dario MALDONADO and Pierre PESTIEAU. Taxing sin goods and subsidizing health care.

2008/32. Jean J. GABSZEWICZ, Didier LAUSSEL and Nathalie SONNAC. The TV news scheduling game when the newscaster's face matters.

2008/33. Didier LAUSSEL and Joana RESENDE. Does the absence of competition in the market foster competition for the market? A dynamic approach to aftermarkets.

2008/34. Vincent D. BLONDEL and Yurii NESTEROV. Polynomial-time computation of the joint spectral radius for some sets of nonnegative matrices.

2008/35. David DE LA CROIX and Clara DELAVALLADE. Democracy, rule of law, corruption incentives and growth.

2008/36. Jean J. GABSZEWICZ and Joana RESENDE. Uncertain quality, product variety and price competition.

2008/37. Gregor ZOETTL. On investment decisions in liberalized electricity markets: the impact of price caps at the spot market.

2008/38. Helmuth CREMER, Philippe DE DONDER, Dario MALDONADO and Pierre PESTIEAU. Habit formation and labor supply.

2008/39. Marie-Louise LEROUX and Grégory PONTHIERE. Optimal tax policy and expected longevity: a mean and variance approach.

2008/40. Kristian BEHRENS and Pierre M. PICARD. Transportation, freight rates, and economic geography.

\section{Books}

Y. POCHET and L. WOLSEY (eds.) (2006), Production planning by mixed integer programming. New York, Springer-Verlag.

P. PESTIEAU (ed.) (2006), The welfare state in the European Union: economic and social perspectives. Oxford, Oxford University Press.

H. TULKENS (ed.) (2006), Public goods, environmental externalities and fiscal competition. New York, Springer-Verlag.

V. GINSBURGH and D. THROSBY (eds.) (2006), Handbook of the economics of art and culture. Amsterdam, Elsevier.

J. GABSZEWICZ (ed.) (2006), La différenciation des produits. Paris, La découverte.

L. BAUWENS, W. POHLMEIER and D. VEREDAS (eds.) (2008), High frequency financial econometrics: recent developments. Heidelberg, Physica-Verlag.

P. VAN HENTENRYCKE and L. WOLSEY (eds.) (2007), Integration of AI and OR techniques in constraint programming for combinatorial optimization problems. Berlin, Springer.

\section{CORE Lecture Series}

C. GOURIÉROUX and A. MONFORT (1995), Simulation Based Econometric Methods.

A. RUBINSTEIN (1996), Lectures on Modeling Bounded Rationality.

J. RENEGAR (1999), A Mathematical View of Interior-Point Methods in Convex Optimization.

B.D. BERNHEIM and M.D. WHINSTON (1999), Anticompetitive Exclusion and Foreclosure Through Vertical Agreements.

D. BIENSTOCK (2001), Potential function methods for approximately solving linear programming problems: theory and practice.

R. AMIR (2002), Supermodularity and complementarity in economics.

R. WEISMANTEL (2006), Lectures on mixed nonlinear programming. 